\title{
Novel Analytical Approach for Characterising Air Entrainment into a Balcony Spill Plume
}

\author{
S. KUMAR, P. H. THOMAS and G. COX \\ BRE, Garston, Watford WD25 9XX, UK
}

\begin{abstract}
A novel analytical formulation, hereafter referred to as the curved plume formulation, has been developed for assessing air entrainment into a thermal plume that spills over a balcony edge into an atrium void. The curved plume formulation is based on an analytical treatment for a two-dimensional spill plume, which incorporates layer momentum, does not resort to the Boussinesq approximation and is consistent with the physical engineering theory of plumes. It provides calculations for virtual source. An asymptotic analysis has been performed to determine the plume behaviour in the turning region and in the far field. The results of the curved plume formulation have been compared with CFD predictions from the JASMINE model and the data from reduced-scale experiments. It has been shown that the formulation has reproduced reasonably satisfactorily air entrainment into the spill plume. It has also shown that the virtual source is located approximately three times the layer depth of the approach flow below the balcony in a reasonably good agreement with the reduced-scale experimental data.
\end{abstract}

KEYWORDS: smoke management, spill plume, entrainment, curved plume formulation, JASMINE

\section{NOMENCLATURE LISTING}

\begin{tabular}{|c|c|}
\hline $\begin{array}{l}a, b \\
B\end{array}$ & $\begin{array}{l}\text { Constants in Eq. }(48) \\
w_{f f}^{3}, \text { equation }(11),\left(\mathrm{m}^{3} \mathrm{~s}^{-3}\right)\end{array}$ \\
\hline$c$ & Constant in Eq. (47) \\
\hline$C p$ & Specific heat at constant pressure $\left(\mathrm{kJkg}^{-1} \mathrm{~K}^{-1}\right)$ \\
\hline$D$ & Plume width (m) \\
\hline E & Top-hat entrainment coefficient \\
\hline$F$ & Froude number, $F 0$ - source value \\
\hline$g$ & Acceleration due to gravity \\
\hline$h$ & Normalised horizontal coordinate \\
\hline$L$ & Horizontal length-scale (width, m) \\
\hline$\dot{m}^{\prime}$ & Mass flow rate per unit width $\left(\mathrm{kgs}^{-1} \mathrm{~m}^{-1}\right)$ \\
\hline$\dot{M}^{\prime}$ & Momentum flow rate per unit width $\left(\mathrm{kgs}^{-2}\right)$ \\
\hline$\dot{Q}^{\prime}$ & $\begin{array}{l}\text { Convective heat flow rate per unit width } \\
\left(\mathrm{kWm}^{-1}\right)\end{array}$ \\
\hline$s$ & Distance along the plume trajectory \\
\hline$T$ & Temperature (K) \\
\hline$u$ & Horizontal velocity component $\left(\mathrm{ms}^{-1}\right)$ \\
\hline$v$ & Normalised vertical coordinate \\
\hline
\end{tabular}

\section{INTRODUCTION}

There is, and has been for many years, a lack of consensus on aspects of guidance available on smoke control system design. One crucial aspect is how to estimate the air entrained into the smoke that spills over a balcony edge into a void such as an atrium. This estimation is extremely important in determining the design capacity required for smoke extraction systems in buildings where smoke may spill under a balcony. The differences between competing estimates, and the resulting uncertainties in the estimation of 
spill plume entrainment cause great difficulties for the design of smoke control measures in building complexes. This paper presents a novel analytical "curved plume" formulation for calculating air entrainment into such a plume. The curved plume formulation is compared with predictions from the CFD model JASMINE and experimental data from reduced-scale experiments.

\section{NOVEL ANALYTICAL FORMULATION FOR THE BALCONY SPILL PLUME}

This section provides a curved plume formulation for calculating entrainment into a spill plume rising through an atrium but excluding end effects. The new treatment provides an alternative to the original BRE method [1-7] that was based on the vertical line plume study of Lee and Emmons [8]. It builds on the twodimensional strong plume analysis of Thomas [9] and Thomas and Delichatsios [10]. The sum of the entrainment rates into both the upper and lower sides of the plume is assumed to be constant and a top hat profile assumed.

Figure 1 is a schematic representation of a two-dimensional spill plume emerging from underneath a balcony. Let $\dot{M}^{\prime}, \rho, u, w$ and $D$ represent respectively the momentum, the density, the horizontal and vertical components of velocity, and the cross-stream dimension of the plume. $\dot{M}_{0}^{\prime}, \rho_{0}, u_{0}$ and $D_{0}$ represent respectively initial momentum, density, velocity and depth of the layer. Let $d s$ represent the incremental distance along the axis (trajectory) of the spill plume and $\phi$ represent its angle of rotation from the horizontal.

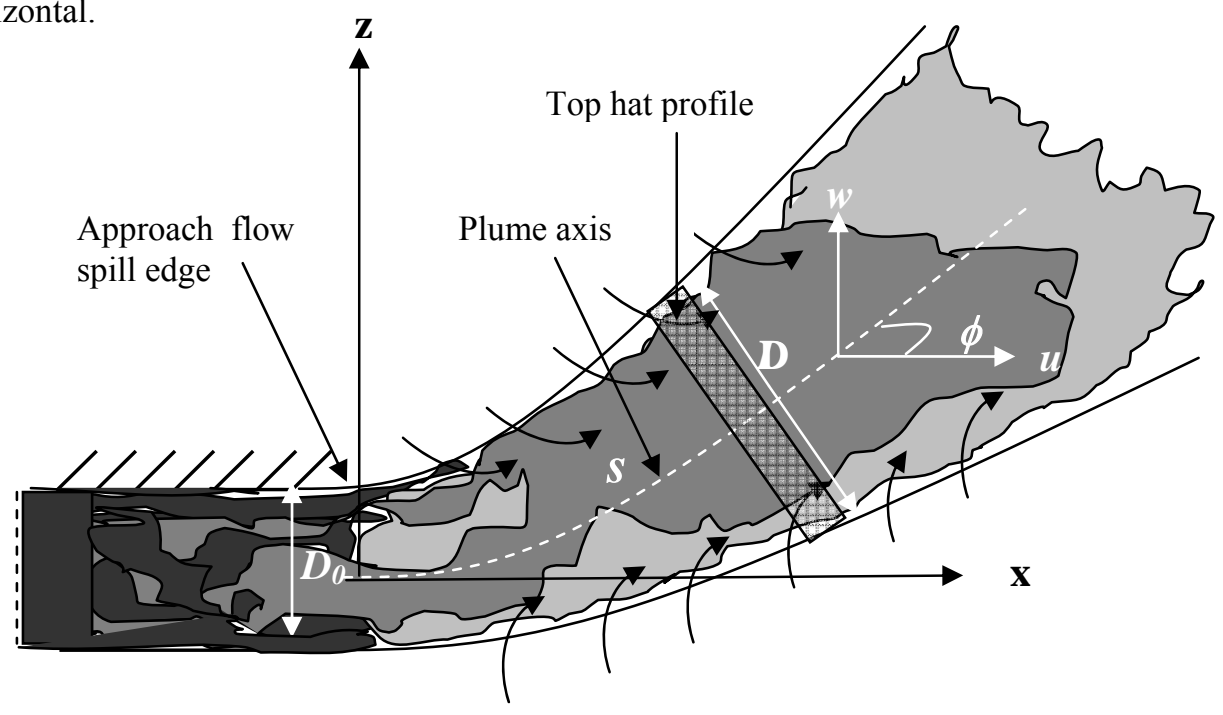

Fig. 1. Schematic description of smoke flowing below a horizontal ceiling into a void.

The mass flow rate per unit width $\left(\dot{m}^{\prime}\right)$ and momentum flow rate per unit width $\left(\dot{M}^{\prime}\right)$ are given by:

$$
\begin{aligned}
& \dot{m}^{\prime}=\rho D\left(u^{2}+w^{2}\right)^{1 / 2} \\
& \dot{M}^{\prime}=\rho D\left(u^{2}+w^{2}\right)
\end{aligned}
$$

The entrainment rate into the spill plume is defined by top-hat profile approximation:

$$
\frac{d \dot{m}^{\prime}}{d s}=2 \rho_{a} E\left(u^{2}+w^{2}\right)^{1 / 2},
$$

where $\rho_{a}$ denotes the ambient density, and $E$ is the top-hat entrainment coefficient which is assumed the same on both upper and lower sides of the plume. Thomas and Delichatsios and [10] have shown that $E$ is $\sqrt{ } 2 E_{G}$, where $E_{G}$ is the Gaussian entrainment coefficient, taken here equal to 0.11 [11].

The horizontal component of the momentum flow rate per width is given by: 
$\dot{M}^{\prime} \cos \phi=\rho D\left(u^{2}+w^{2}\right) \frac{u}{\left(u^{2}+w^{2}\right)^{1 / 2}} \equiv \dot{M}_{0}^{\prime} ; \cos \phi=\frac{u}{\left(u^{2}+w^{2}\right)^{1 / 2}}$

where $\dot{M}_{0}^{\prime}=\rho_{0} D_{0} u_{0}^{2}$

Newton's second law of motion relates the buoyancy force of the plume to its vertical momentum flow rate per unit width, which gives:

$\frac{d \dot{M}^{\prime}}{d s}=g \Delta \rho D \sin \phi ; \sin \phi=\frac{w}{\left(u^{2}+w^{2}\right)^{1 / 2}}$

Using ideal gas law gives:

$\frac{\theta}{T_{a}}=\frac{\Delta \rho}{\rho}$ where $\theta=\mathrm{T}-\mathrm{T}_{\mathrm{a}} ; \Delta \rho=\rho_{\mathrm{a}}-\rho$

$\dot{m}^{\prime} C_{p} \theta=\dot{Q}^{\prime}=\rho D\left(u^{2}+w^{2}\right)^{1 / 2} C_{p} T_{a} \Delta \rho / \rho$

where $C_{p}$ is the mean specific heat at constant pressure, $\theta$ is the gas temperature rise above ambient and $\rho$ is the gas density in the plume, and $\dot{Q}^{\prime}$ is the convective heat flow rate per unit width in the hot layer feeding into the balcony spill plume. Using Eq. (7), Eq. (5) becomes

$$
\begin{aligned}
\frac{d \dot{M}^{\prime}}{d s} & =\frac{g \dot{Q}^{\prime} \sin \phi}{C_{p} T_{a}\left(u^{2}+w^{2}\right)^{1 / 2}} \\
\frac{d \dot{M}^{\prime}}{d s} & =\frac{g \dot{Q}^{\prime} w}{C_{p} T_{a}\left(u^{2}+w^{2}\right)}
\end{aligned}
$$

Eliminating ds between Eq. (3) and Eq. (9) yields

$$
\frac{d \dot{M}^{\prime}}{d \dot{m}^{\prime}}=\frac{g \dot{Q}^{\prime}}{2 E \rho_{a} C_{p} T_{a}} \frac{w}{\left(u^{2}+w^{2}\right)^{3 / 2}}=B \frac{w}{\left(u^{2}+w^{2}\right)^{3 / 2}}=B \frac{\left(D w^{2}\right)^{1 / 2} D}{\left(D\left(u^{2}+w^{2}\right)\right)^{3 / 2}}
$$

where

$$
B=\frac{g \dot{Q}^{\prime}}{2 E \rho_{a} C_{p} T_{a}} \equiv w_{f f}^{3}
$$

Combining Eqs. (4) and (4a) gives

$$
\rho^{2} D^{2}\left(u^{2}+w^{2}\right) u^{2}=\rho_{0} D_{0}^{2} u_{0}^{4}
$$

which can be rewritten as

$\rho^{2} D^{2}\left(u^{2}+w^{2}\right)\left(u^{2}+w^{2}\right)-\rho^{2} D^{2}\left(u^{2}+w^{2}\right) w^{2}=\rho_{0} D_{0}^{2} u_{0}^{4}$

or using eq (2),

$$
\begin{aligned}
& \dot{M}^{\prime 2}-\rho D w^{2} \dot{M}^{\prime}=\dot{M}_{0}^{\prime 2} \text {, or } \\
& \rho D w^{2}=\frac{\dot{M}^{\prime 2}-\dot{M}_{0}^{\prime 2}}{\dot{M}^{\prime}}
\end{aligned}
$$

The value of $D$ can be obtained by rearranging Eqs. (1) and (2):

$$
D=\frac{\dot{m}^{\prime 2}}{\rho \dot{M}^{\prime}}
$$


Exploiting square-root of Eqs. (2) and (13), Eq. (10) becomes

$$
\frac{d \dot{M}^{\prime}}{d \dot{m}^{\prime}}=B \frac{m^{\prime 2}}{\dot{M}^{\prime 2}}\left(1-\frac{\dot{M}_{0}^{\prime 2}}{\dot{M}^{\prime 2}}\right)^{1 / 2}
$$

By using the transformation:

$$
\dot{M}^{\prime}=\dot{M}_{0}^{\prime} \cosh \phi \text {, }
$$

Eq. (15) can be integrated to give the following generalised solution for the spill plume between the mass flow rate per unit width $\left(\dot{m}^{\prime}\right)$ and momentum flow rate per unit width $\left(\dot{M}^{\prime}\right)$ :

$$
B\left(\dot{m}^{\prime 3}-\dot{m}_{0}^{\prime 3}\right)=\dot{M}^{\prime 3}\left(1-\frac{\dot{M}_{0}^{\prime 2}}{\dot{M}^{\prime 2}}\right)^{1 / 2}\left(1+\frac{2 \dot{M}_{0}^{\prime 2}}{M^{\prime 2}}\right)
$$

It can be noted that the above generalised solution for the spill plume reduces to the vertical plume solution in the limit of $\dot{M}_{0}^{\prime} \rightarrow 0$ and $\dot{m}_{0}^{\prime} \rightarrow 0$, or $\dot{M}^{\prime} \rightarrow \infty$ and $\dot{m}^{\prime} \rightarrow \infty$, i.e.,

$$
B \dot{m}^{\prime 3}=\dot{M}^{\prime 3} \Rightarrow B=\left(\dot{M}^{\prime} / \dot{m}^{\prime}\right)^{3}=w_{f f}^{3} \Rightarrow w_{f f}=B^{1 / 3},
$$

which is the solution for a vertical plume.

We can obtain the vertical distance $z$ by rewriting

$$
\frac{d \dot{M}^{\prime}}{d z}=\frac{d \dot{M}^{\prime}}{d s} / \frac{d z}{d s}=\frac{d \dot{M}^{\prime}}{d s} / \sin \phi
$$

which, by first using Eq. (5), and then using Eqs. (1), (2), (7) and (11), becomes

$$
\frac{d \dot{M}^{\prime}}{d z}=g D \Delta \rho=2 E \rho_{a} B \frac{\dot{m}^{\prime}}{\dot{M}^{\prime}}
$$

or by integrating with respect to $\dot{M}^{\prime}$, we get

$$
z=\frac{1}{2 E \rho_{a} B} \int_{\dot{M}_{0}^{\prime}}^{\dot{M}^{\prime}} \frac{\dot{M}^{\prime} d \dot{M}^{\prime}}{\dot{m}^{\prime}}
$$

Similarly,

$$
\frac{d x}{d \dot{M}^{\prime}}=\frac{d x}{d s} / \frac{d \dot{M}^{\prime}}{d s}=\frac{\cos \phi}{d \dot{M}^{\prime} / d s}=\left(\frac{\dot{M}_{0}^{\prime}}{2 E \rho_{a} B}\right) \frac{1}{\dot{m}^{\prime}\left(1-\dot{M}_{0}^{\prime 2} / \dot{M}^{\prime 2}\right)^{1 / 2}}
$$

or by integrating with respect to $\dot{M}^{\prime}$, we get

$$
x=\left(\frac{\dot{M}_{0}^{\prime}}{2 E \rho_{a} B}\right) \int_{\dot{M}_{0}^{\prime}}^{\dot{M}^{\prime}} \frac{d \dot{M}^{\prime}}{\dot{m}^{\prime}\left(1-\dot{M}_{0}^{\prime 2} / \dot{M}^{\prime 2}\right)^{1 / 2}}
$$

Eqs. (21) and (23) define the trajectory of the spill plume. Eq. (23) demonstrates that the spill plume continues to bend away from the vertical. This feature has either been ignored or neglected in the original BRE method. For simplicity, we express Eqs. (21) and (23) in non-dimensional form by introducing nondimensional vertical and horizontal coordinates, $\mathrm{v}$ and $\mathrm{h}$, as defined by the following equations:

$$
v=\frac{2 E \rho_{a} B^{2 / 3}}{\dot{M}_{0}^{\prime}} z=2 E \frac{\rho_{a}}{\rho_{0}}\left(\frac{w_{f f}}{u_{0}}\right)^{2} \frac{z}{D_{0}}
$$


$h=\frac{2 E \rho_{a} B^{2 / 3}}{\dot{M}_{0}^{\prime}} x=2 E \frac{\rho_{a}}{\rho_{0}}\left(\frac{w_{f f}}{u_{0}}\right)^{2} \frac{x}{D_{0}}$

We now introduce non-dimensional momentum flow rate parameter, $\alpha$, and mass flow rate parameters, $\beta$,:

$$
\begin{aligned}
& \alpha=\frac{\dot{M}^{\prime}}{\dot{M}_{0}^{\prime}} \\
& \beta=\frac{B^{1 / 3} \dot{m}^{\prime}}{\dot{M}_{0}^{\prime}}=\left(\frac{w_{f f}}{u_{0}}\right)\left(\frac{\dot{m}^{\prime}}{\dot{m}_{0}^{\prime}}\right)
\end{aligned}
$$

The generalised spill plume solution, Eq. (17), can then be written in non-dimensional form as:

$\beta^{3}=\left(\frac{w_{\text {ff }}}{u_{0}}\right)^{3}+\alpha^{3}\left(1-1 / \alpha^{2}\right)^{1 / 2}\left(1+2 / \alpha^{2}\right)$

Eqs. (21) and (23) become in non-dimensional form as:

$$
\begin{aligned}
& v=\int_{1}^{\dot{M}^{\prime} / \dot{M}_{0}^{\prime}} \frac{\alpha d \alpha}{\beta} \\
& h=\int_{1}^{\dot{M}^{\prime} / M_{0}^{\prime}} \frac{d \alpha}{\beta\left(1-1 / \alpha^{2}\right)^{1 / 2}}
\end{aligned}
$$

\section{Plume behaviour near the turning region $(\alpha \rightarrow 1)$}

Let us reconsider Eqs. (28) to (30), by expressing $\alpha$ as:

$\alpha=1+\varepsilon$, where $\varepsilon<<1$

$\beta \approx \frac{w_{\text {ff }}}{u_{0}}$,

$v \approx \frac{u_{0}}{w_{f f}} \varepsilon$, when $\varepsilon \rightarrow 0$

$h \approx \frac{u_{0}}{w_{f f}}(2 \varepsilon)^{1 / 2}$, when $\varepsilon \rightarrow 0$

By dividing Eq. (33) by the square of Eq. (34), we get

$v \approx \frac{1}{2} \frac{w_{\text {ff }}}{u_{0}} h^{2}$, when $\varepsilon \rightarrow 0$ or $\alpha \rightarrow 1$

Plume behaviour far from the turning region $(\alpha \rightarrow \infty)$

$\beta \approx \alpha$, where $\alpha>>1$

$v \approx \alpha$, when $\alpha \rightarrow \infty$

$h \approx \ln \alpha$, when $\alpha \rightarrow \infty$

Substituting Eq. (37) into Eq. (38), we get

$h \propto \ln v$, or $v \propto e^{k h}$ when $\alpha \rightarrow \infty, k$ being a constant. 


\section{Virtual Source Location, $\mathrm{z}_{0}$}

It is common practice in discussing plumes to relate the mass flow rate in the far field with the actual height, $z$, from the source (say, balcony edge), corrected when necessary by an effective displacement $z_{0}$ so that

$$
\dot{m}^{\prime} \propto\left(z+z_{0}\right)
$$

The effects of various initial conditions, e.g., finite mass flow rate and finite source size, are incorporated into $z_{0}$. To find the virtual source location, we first express the conventional line plume in the same terms as used here. From the entrainment relationship, we have

$$
\frac{d \dot{m}^{\prime}}{d z}=2 E \rho_{a} w
$$

with $w=w_{f f}$ for a vertical line plume $\left(\dot{m}_{0}^{\prime}=0\right)$ in the far field.

The entrained mass flow rate per unit width for the neutral virtual plume, i.e., the plume emerging from a virtual source situated conventionally at a distance $z_{0}$ below the horizontal source (situated at half the ceiling layer depth $D_{0}$ below the balcony), is

$$
\begin{aligned}
& 2 E \rho_{a}\left(z+z_{0}\right) w_{f f}=\dot{m}^{\prime}=\frac{\dot{M}^{\prime}}{w_{f f}} \\
& z_{0}=\frac{\dot{M}^{\prime}}{2 E \rho_{a} B^{2 / 3}}-\frac{1}{2 E \rho_{a} B} \int_{M^{\prime}}^{M^{\prime}} \frac{\dot{M}^{\prime} d \dot{M}^{\prime}}{\dot{m}^{\prime}} \\
& =\frac{1}{2 E \rho_{a} B^{2 / 3}}\left(\int_{M^{\prime}}^{\dot{M}^{\prime}} d \dot{M}^{\prime}+\dot{M}_{0}^{\prime}-\frac{1}{w_{f f}} \int_{M^{\prime}}^{\dot{M}_{0}^{\prime}} \frac{\dot{M}^{\prime} d \dot{M}^{\prime}}{\dot{m}^{\prime}}\right) \\
& \frac{2 E \rho_{a} z_{0}}{D_{0} \rho_{0}}\left(\frac{w_{f f}}{u_{0}}\right)^{2}=\left[1+\int_{1}^{\infty}\left(1-\frac{\alpha}{\beta}\right) d \alpha\right]
\end{aligned}
$$

Note that $z_{0}$ is most important for the near field where the plume momentum is large. So, replacing the upper limit of the integral in the above equation by $\infty$ (instead of $\alpha$ ) is a reasonable approximation. The evaluation of the integral on the right shows that it is not very sensitive to the choice of independent parameter $\left(w_{f f} / u_{0}\right)$ to which it depends. Equation can be rewritten to give a theoretically based expression for the virtual source, $z_{0}$, :

$$
\frac{z_{0}}{D_{0}}=\frac{\rho_{0}}{2 E \rho_{a}}\left(\frac{u_{0}}{w_{f f}}\right)^{2}\left[1+\int_{1}^{\infty}\left(1-\frac{\alpha}{\beta}\right) d \alpha\right] .
$$

We can now compare this more theoretically based expression with other empirically-based expressions for $z_{0}$. Poreh et al [11] have shown that

$$
z_{0}=D_{0}+\frac{\dot{m}_{0}^{\prime}}{c \dot{Q}^{\prime 1 / 3}},
$$

where $\dot{Q}^{\prime}$ is the rate of thermal energy flow into the ceiling layer below the balcony, and $c$ is a constant $0.3 c_{m} \mathrm{~L}^{2 / 3}$, $\mathrm{L}$ being the horizontal length-scale (width) of the plume at the source (say, the balcony edge), and $c_{m}$ an entrainment coefficient taken as $0.49<c_{m}<0.51$.

Thomas et al [12] suggested, by analysing Morgan et al data [1,3,5] that

$$
\frac{D_{0} \dot{Q}^{\prime 1 / 3}}{\dot{m}_{0}^{\prime}}=a\left(1+\frac{b \dot{Q}^{\prime}}{c_{p} T_{a} \dot{m}_{0}^{\prime}}\right)
$$

where $a$ and $b$ are constants. $a=2.5$, and $b=1$, thus giving the following expression: 


$$
\frac{D_{0} \dot{Q}^{\prime 1 / 3}}{\dot{m}_{0}^{\prime}}=2.5\left(1+\frac{\dot{Q}^{\prime}}{c_{p} T_{a} \dot{m}_{0}^{\prime}}\right)=2.5 \frac{T_{0}}{T_{a}}=2.5 \frac{\rho_{a}}{\rho_{0}}
$$

and bearing in mind the earlier comments on the transformation of cross-sections of plumes, we have, here, a convenient simple consistency of

$$
\frac{D_{0} \rho_{0}}{\rho_{a}} \frac{\dot{Q}^{\prime 1 / 3}}{\dot{m}_{0}^{\prime}}=2.5
$$

By using Eq. (50), Poreh et al Eq. (47) becomes

$$
\frac{z_{0}}{D_{0}}=1+2.7 \frac{\rho_{0}}{\rho_{a}}
$$

Thomas et al analysis suggests that

$$
0.16 \frac{z_{0}}{D_{0}}=\frac{1.4}{2.5} \frac{\rho_{0}}{\rho_{a}}+0.0014 \frac{\dot{Q}^{\prime 2 / 3}}{D_{0}}
$$

The last term is statistically significant but small. Ignoring the last term, Eq. (52) becomes

$$
\frac{z_{0}}{D_{0}} \approx 3.5 \frac{\rho_{0}}{\rho_{a}}
$$

It can be noted that for $\rho_{0} / \rho_{a}=0.8$, Eqs. (51) and (53) give $z_{0} / D_{0} \approx 2.8$ which is close to the average value of 2.6 suggested by the data of Poreh et al. [11]. The value obtained from Eq. (46) from this study gives, for $D_{0}$ ranging between $0.11 \mathrm{~m}$ and $0.17 \mathrm{~m}$, and experimental values of $\rho_{0} / \rho_{a}$ ranging between 0.5 and 0.85 , the value of $z_{0} / D_{0} \approx 2.8 \pm 0.5$. Bear in mind that the theoretical origin in Eq. (46) is shifted downward from the spill edge by $D_{0} / 2$. The vertical distance measured from the spill edge (taken as the origin in Eqs. (51) and (53) and also in experiments [13 -15] used in this study) will be represented by the symbol $z_{\mathrm{e}}$, where

$z_{e}=z+D_{0} / 2$, and $z_{e 0}=z_{0}+D_{0} / 2$.

\section{COMPARISONS WITH EXPERIMENT AND CFD}

\section{Details of experiment considered}

Two sets of experiments were considered for the validation of the present curved plume formulation. The earlier set was described in detail by Marshall et al [13] and Marshall and Harrison [14] and the later by Harrison and Spearpoint [15]. Both sets represented the $1 / 10^{\text {th }}$ scale model of the equivalent full scale experiment, simulating a fire within a room with an opening and the resulting smoke plume spilling from under the balcony over to an adjacent atrium void. The model experiment used the modified Froude number scaling and ensured that the equivalent fluid flow was fully turbulent on the model scale. The apparatus used for both the sets were similar, the latter based on the extension of the former to allow for varying width of the spill plume. A vertical section of the experimental rig is shown in Fig. 2.

The fire compartment was made of the $20 \mathrm{~mm}$ thick ceramic fibre insulation (CFI) board with a $2 \mathrm{~mm}$ steel substrate on each external face. Harrison and Spearpoint [15] provided comprehensive set of data by varying the fire's heat release rate $(\dot{Q})$ between $5 \mathrm{~kW}$ and $15 \mathrm{~kW}$, varying the width of the compartment opening (controlling the width of the spill plume) between $0.2 \mathrm{~m}$ and $1.0 \mathrm{~m}$, and the rise of the spill plume above the balcony edge at the nominal height of $0 \mathrm{~m}, 0.3 \mathrm{~m}, 0.5 \mathrm{~m}, 0.7 \mathrm{~m}, 0.9 \mathrm{~m}$ and $1.2 \mathrm{~m}$. Since the experiments indicated plug holing for the height of rise of $1.2 \mathrm{~m}$, these were not considered for comparison with the analytical and CFD results.

An ethanol pool fire, producing steady heat release rates of $5 \mathrm{~kW}$ to $15 \mathrm{~kW}$ was used as a fire source inside the fire compartment. Gas velocities and temperatures were measured in the approach flow and these were used as boundary conditions for the numerical simulations.. The measured velocities and temperatures indicated convective heat flow rate of some $75 \%$ of $\dot{Q}$ for the compartment opening width of $1 \mathrm{~m}$ and 
some $60 \%$ of $\dot{Q}$ for the compartment opening width of $0.2 \mathrm{~m}$. Please note that the calculations presented in this study use the convective heat flow rates. Their values for the three heat release rates $(5,10,15 \mathrm{~kW})$ for the opening width of 1.0 and $0.2 \mathrm{~m}$ can be found on the figures in the results section. The mass extract rate in the hood was measured for plume heights of rise ranging between $0 \mathrm{~m}$ and $0.9 \mathrm{~m}$. In each case the movable smoke exhaust hood walls (shown in Fig. 2) were adjusted such that the observed smoke layer was just contained in the hood (i.e., without significant overflow from the bottom of the hood).

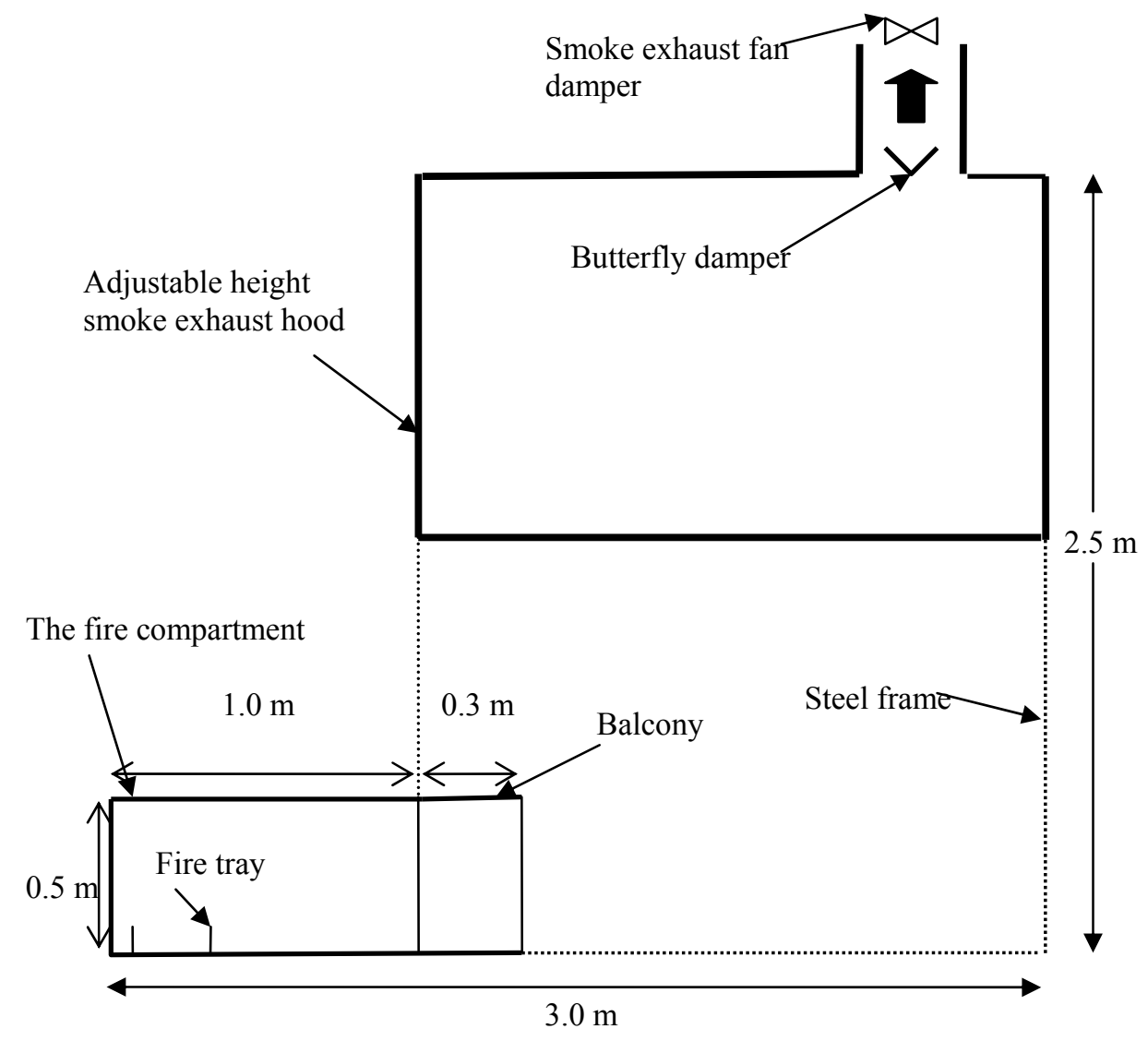

Fig. 2. Schematic of the experimental rig.

\section{Details of CFD Formulation}

The new curved plume analysis has been assessed by comparing it with the CFD model JASMINE. A description of the CFD fire modelling method, used by JASMINE, has been given elsewhere [eg 16] and is not repeated in detail here. Suffice it to say that JASMINE is a Reynolds Averaged Navier Stokes finite volume code employing a Cartesian grid. The physical and numerical sub-models employed in this study are:

$>\mathrm{k}, \varepsilon$ turbulence model.

$>$ upwind differencing for the convection terms in the discretized conservation equations.

$>$ buoyancy related source terms in the momentum and turbulence equations.

convection and radiation heat losses to the solid boundaries of the hood.

JASMINE had earlier been applied by Miles et al [17] to the more limited data set of Marshall et al [13] and Marshall \& Harrison [14]. In this study, each JASMINE simulation was defined uniquely by the grid arrangement, the mass/heat source (at the fire compartment exit), the placement of the hood front/rear walls and the initial mass extraction rate. To define the problem properly, fixed-pressure (open) boundary 
conditions were imposed at the limits of the computational domain, set some distance away from the apparatus. These boundaries were imposed at all domain limits except at the bottom (solid floor) and a symmetry plane halfway across the width of the fire compartment and the hood. A total of approximately 200,000 grid cells for the coarse grid and 315,000 grid cells for the fine grid were used to represent half of the geometry modelled.

Only steady state CFD simulations were performed. The first set involved fires with total heat release rates ranging from approximately $5 \mathrm{~kW}$ to $40 \mathrm{~kW}$, but channeling screens being kept at a fixed width of $0.91 \mathrm{~m}$. The second set of experiments was performed for a fixed heat release rate of $10 \mathrm{~kW}$ but a varying width of the channeling screens ranging between $0.2 \mathrm{~m}$ and $1.0 \mathrm{~m}$. Since the reduced scale experiments measured the profiles of the gas velocity and temperatures of the approach flow at the balcony edge, it was not necessary to model the fire compartment. Instead these gas velocities and temperatures defined the mass flux and the convective heat flux at the compartment exit plane as inlet boundary conditions for the CFD simulations.

The mass extract rate in the hood exit duct was set initially to the value obtained from the analytical method. This was then adjusted by $5 \%$ increments/decrements until the iso-surface of 1 degree Centigrade rise, characterizing smoke layer interface, coincided the bottom of hood as shown in Fig. 3. The velocity vector plots coloured with temperatures were also used to characterise the smoke layer interface.
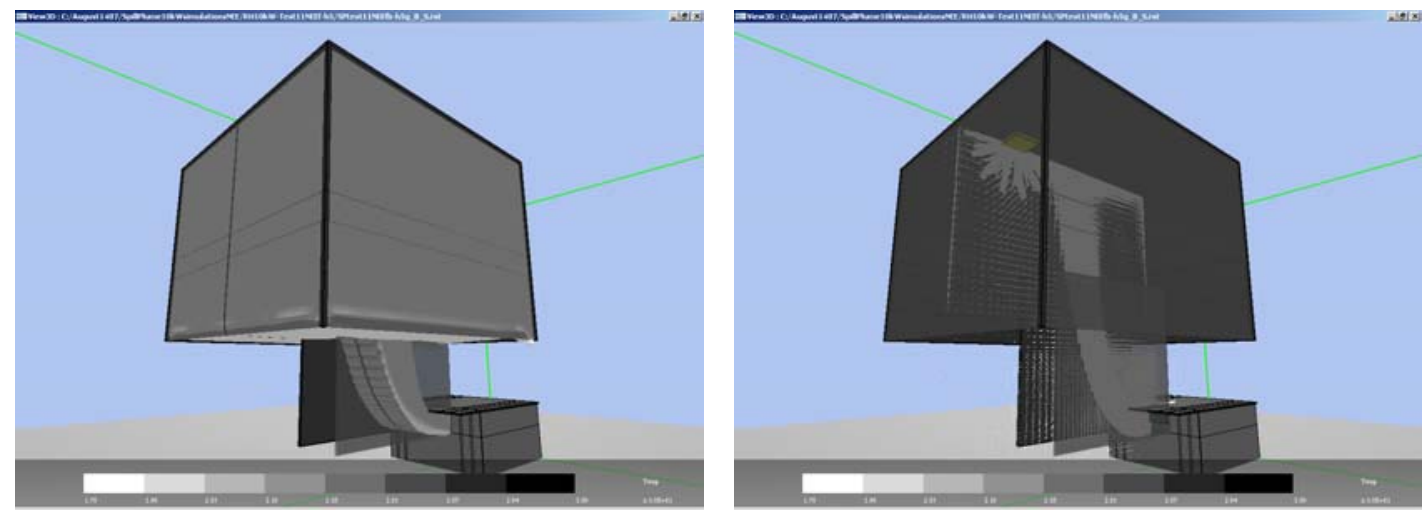

Fig. 3. The predicted 1 degree $\mathrm{C}$ rise iso-surface (left) and velocity vectors coloured with temperatures (right) on monochrome grey-scale for the $10 \mathrm{~kW}$ fire for the plume height of rise of $0.5 \mathrm{~m}$.

Figures 4 to 6 show the comparison of the calculated mass entrainment from the analytical formulations, denoted by lines, with the experimental data, denoted by symbols, where $\mathrm{z}_{\mathrm{e}}$ denotes the height of rise of the spill plume from the balcony edge. The parallel lines result from differing horizontal momentum in the approach flow. Miles et al [17] have already discussed the comparison of the CFD results with the experimental data of Marshall et al [13] and Marshal and Harrison [14], and have therefore not been included in Fig. 4. The CFD results are, however, included in Figs. 5 and 6 to show that analytical formulation is in good agreement with both the CFD results and the measured data. Figs. 4 and 5 suggest that the virtual source for the excess mass entrainment rate in the spill plume is located at a distance $\mathrm{D}_{0}$ below the balcony edge, where $\mathrm{D}_{0}$ is the layer depth of the approach flow below the balcony edge. Whereas, the virtual source for the total mass entrainment rate in the spill plume is located at a distance $z_{0}$ below the balcony edge where $z_{0}$ is approximately equal to $3 D_{0}$, as shown by equation (44). This is supported by Fig. 7 which shows the comparison of $z_{e 0}$ obtained from the analytical formulation with empirical formulations of Poreh et al [11] and Thomas et al [12]. Thus, it seems reasonable to recommend $z_{0} / D_{0} \approx 2.8$ from balcony level over a wide range of $F_{0}$, although there does appear an unexplained systematic difference for the case of total heat release rate of $15 \mathrm{~kW}$.

\section{CONCLUSIONS}

A novel analytical formulation has been developed for calculating the air entrainment into a curved plume that spills over a balcony edge into an atrium void. The formulation has also provided expressions for virtual source location for the spill plume. An asymptotic analysis has been performed to determine the plume behaviour in the turning region and in the far field. 


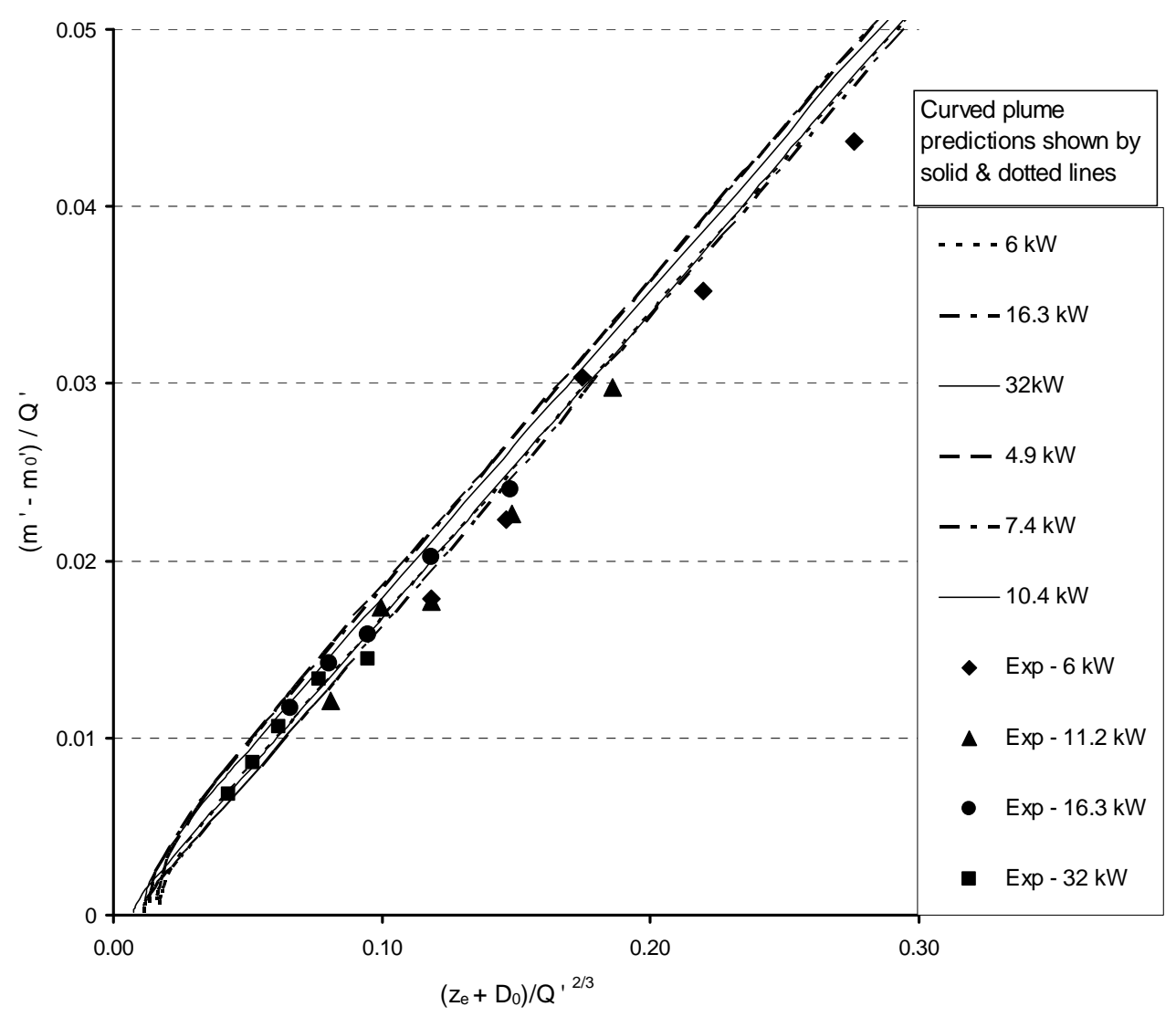

Fig. 4. Comparison of calculated entrained mass flux per unit length using the curved plume formulation with earlier measurements[13,14].

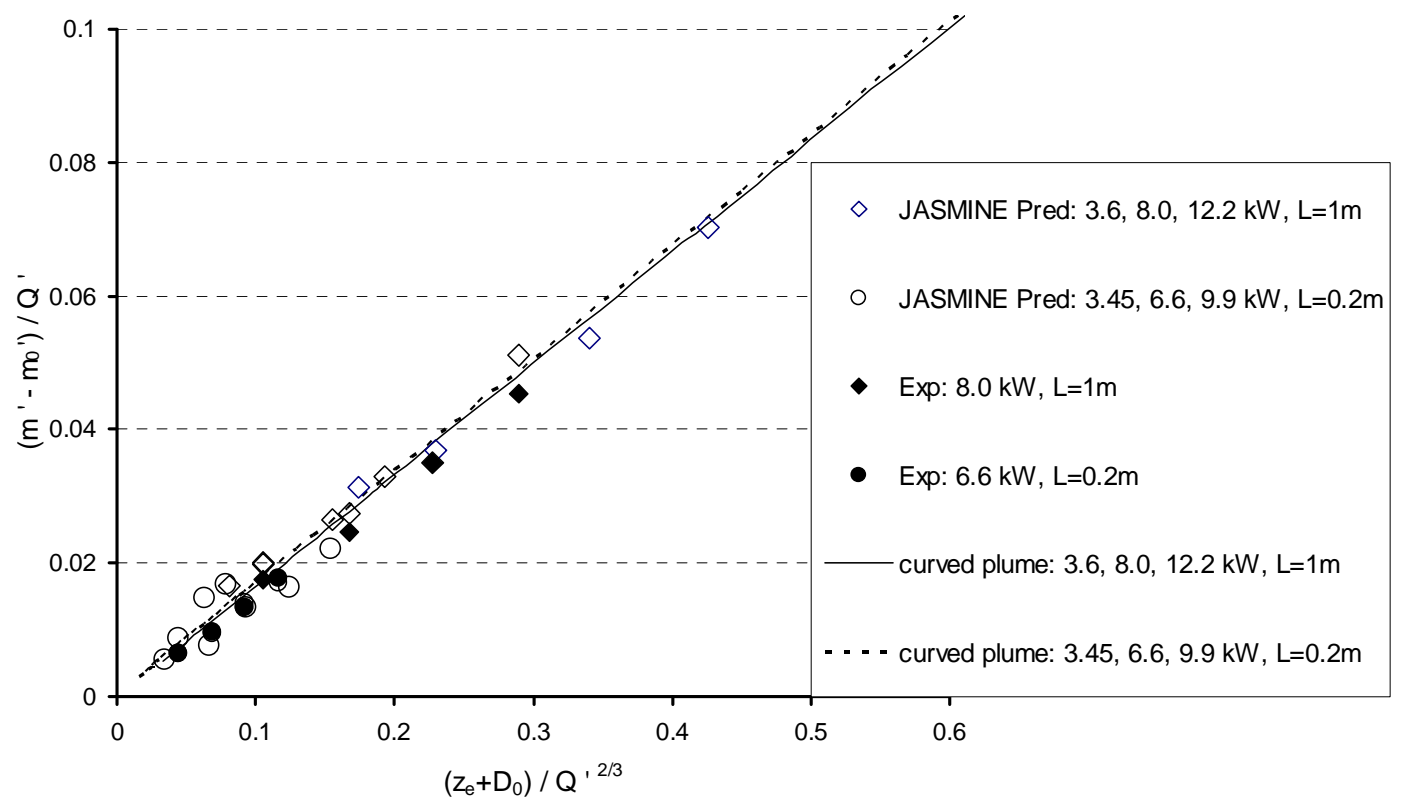

Fig. 5. Comparison of calculated entrained mass flux per unit length using the curved plume formulation with CFD model JASMINE and measurements [15]. 


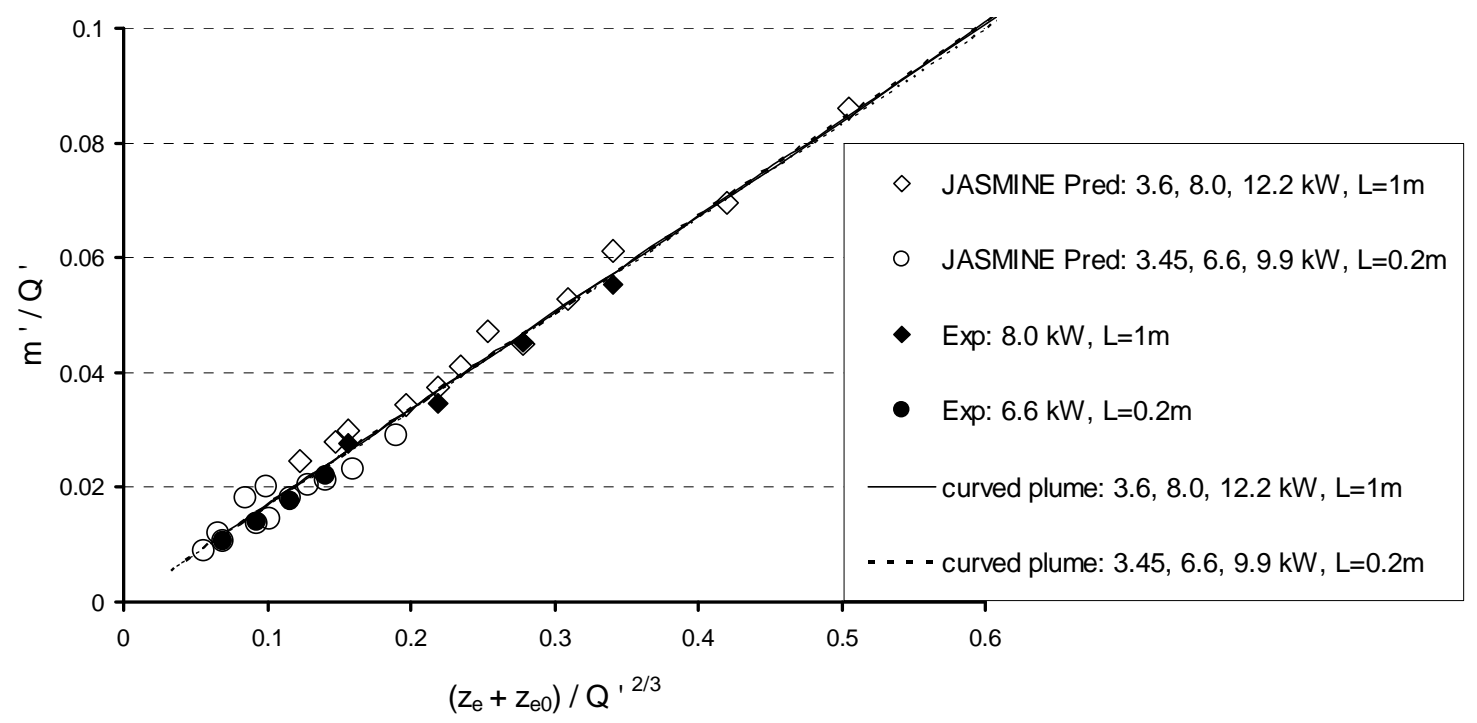

Fig. 6. Comparison of calculated total mass flux per unit length using the curved plume formulation with CFD model JASMINE and measurements [15].

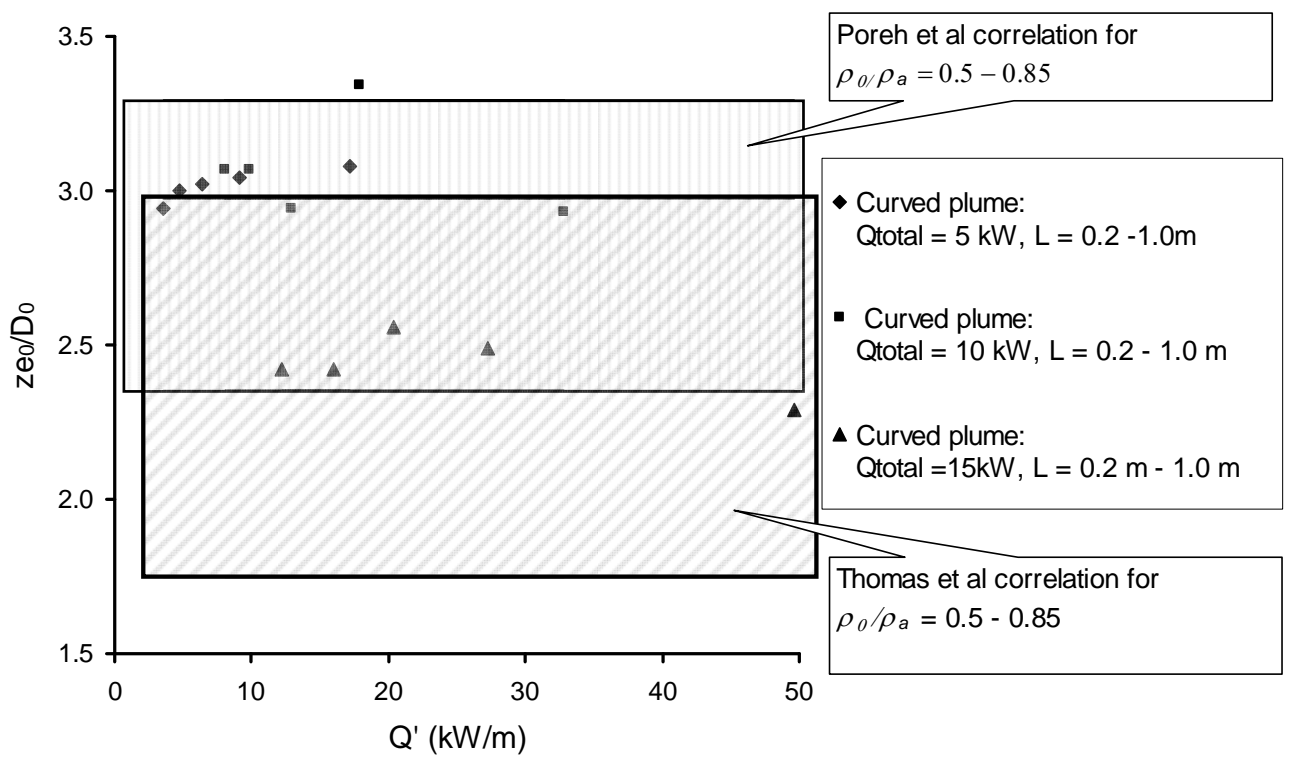

Fig. 7. Comparison of the calculated virtual source location from curved plume formulation with empirical correlations.

It has been shown that the analytical formulation, which currently excludes the end effects, has satisfactorily reproduced the experiments of Marshall et al [13] and Marshall \& Harrison [14] and Harrison and Spearpoint [15] and the CFD simulations. The virtual source location obtained from the curved plume formulation appears to be approximately three times the smoke layer depth below the balcony edge, and is in reasonable agreement with the empirical correlation from the published literature. It is recommended that full-scale experiments be conducted to evaluate the performance of the analytical formulation for 
different width of fire compartments, for larger height of rise and for different fire strength to the effect of plume trajectories on the overall spill plume entrainment.

\section{ACKNOWLEDGEMENT}

The authors would like to thank Mr R Harrison and Dr M Spearpoint of the University of Canterbury, for providing data from their experimental study of balcony spill plumes, which they have submitted for presentation at this Symposium, and will form part of Mr Harrison's PhD Thesis.

\section{REFERENCES}

[1] Morgan, H.P. and Marshall, N.R., "Smoke control measures in covered two-storey shopping mall having balconies as pedestrian walkways", BRE Current Paper 11/79, Garston, BRE, 1979.

[2] Hansell, G.O., Marshall, N.R. and Morgan, H.P., "Smoke flow experiments in a model atrium", BRE Occasional Paper OP55, Garston, BRE, 1993.

[3] Morgan, H.P. and Marshall, N.R., "Smoke hazards in covered multilevel shopping malls: an experimentally-based theory for smoke production”, BRE Current Paper 48/75, Garston, BRE, 1975.

[4] Morgan H.P. and Hansell, G.O., (1987) Atrium buildings: calculating smoke flows in atria for smoke control design, Fire Safety Journal 12 : 9-35doi:10.1016/0379-7112(87)90013-0

[5] Marshall N R, Harrison R and Morgan H P, "A Study of the Mechanisms that Govern the Entrainment of Air into a Thermal Line Plume", Note N 65/93, Building Research Establishment, 1993.

[6] Hansell, G.O. and Morgan, H. P., "Design approaches for smoke control in atrium buildings", BRE Report BR 258. Garston, CRC, 1994.

[7] Morgan H.P., Ghosh B.K., Garrad G., Pamlitscha R., De Smedt J-C and Schoonbaert L.R., "Design Methodologies for smoke and heat exhaust ventilation", BRE Report BR 368, Garston, CRC, 1999.

[8] Lee S.L. and Emmons H.W., (1961) A study of natural convection above a line fire, J Fluid Mechanics, 10: 353.doi:10.1017/S0022112061000573

[9] Thomas P.H., (2000) "On strong two-dimensional plumes", Fire Safety Journal, 34: 47. doi:10.1016/S0379-7112(99)00050-8

[10] Thomas, PH. and Delichatsios, (2007) M., Notes on the similarity of turbulent buoyant fire plumes with large density variations, Fire Safety Journal, 42: 43-50.doi:10.1016/j.firesaf.2006.08.001

[11] Poreh M., Morgan, H.P., Marshall N.R. and Harrison, (1998) Entrainment by two-dimensional spill plumes, Fire Safety journal, 30: 1.doi:10.1016/S0379-7112(97)00036-2

[12] Thomas P.H., Morgan H.P. and Marshall N.R., (1998) The spill plume in smoke control design, Fire Safety Journal, 30: 21.doi:10.1016/S0379-7112(97)00037-4

[13] Marshall, N.R., Harrison, R. and Morgan H P, "A Study of the Mechanisms that govern the Entrainment of Air into a Thermal Line Plume", Note N 65/93, Building Research Establishment 1993.

[14] Marshall, N.R. and Harrison, R., "A Study to Investigate Entrainment into a Two-Dimensional Hot Thermal Line Plume”, Client Report CR 23/94, Building Research Establishment, 1994.

[15] Harrison. R. and Spearpoint, M., Characterisation of balcony spill plume entrainment using physical scale modelling, , $9^{\text {th }}$ International Symposium on Fire Safety Science, IAFSS, Germany, 2008.

[16] Cox, G. and Kumar, S., (1987) Field Modelling of Fire in Forced Ventilated Enclosures, Combustion Science \& Technology, 52: 7.doi:10.1080/00102208708952565

[17] Miles, S., Kumar, S. and Cox, G., 1997. The Balcony Spill Plume-Some CFD Simulations, Fire Safety Science 5: 237-247. 